\title{
ADIABATIC CALORIMETRIC DETERMIMATION OF PHASE BEHAVIOR
}

EDGAR F. MESTRUM, JR.

University of Michigan, Department of Chemistry, Ann Arbor, Michigan (USA)

\section{INTROOUCTION}

Although many thermo-analytical techniques (Franzosini, 1983) are useful in the determination of the very existence, the temperatures, $T_{\text {trs }}$, and the associated enthalpies $\Delta_{\text {trs }} H$ of transitions, in single component systems as well as in the composition-dependent phase diagrams of multicomponent systems, the pervasive power and indeed convenience of adiabatic calorimetric delineation needs to be given serious consideration (Westrum, 1984b). Calorimetric methods such as differential thermal analysis (DTA)--either qualitative or so-called quantitative--and differential scanning calorimetry (DSC) are well known and widely accepted tools (Gi11, 1974).

Although formerly the inconvenience of having to fabricate adiabatic calorimetric apparatus and the adjuvant circuitry and having to operate the device over days, if not weeks, by teams of two persons was daunting, the availability of well-designed cryostats for sub-ambient studies (Westrum et al., 1968; Westrum, 1984a) and thermostats for super-ambient, (West and Westrum, 1968; Andrews et al., 1978) of computer controlled operating, data-logging, calculating facilities, (Westrum, 1984c) and an important advance toward miniaturization of the sample size required has changed the perspective significantly. For approximately the same amount of operator time, precise and accurate quantitative data over extended temperature ranges much lower than those accessible to DSC can be obtained under equilibrium conditions with a re- 
liability that usually compensates generously for a somewhat greater involvement and sample size particularly when it enables determination of minute details which by virtue of broadness, smallness, or tendency toward hysteresis, undercooling or superheating would likely go totally undetected by "quicker and dirtier" approaches.

A recent paper by White (White, 1984) contrasts the characterization of OSC vs. adiabatic calorimetry on the study of four transitions near $358 \mathrm{~K}$. She shows that DSC was unable to fully resolve the transitions or their shape and gave limited information on $\Delta_{t r s} H$ and $\Delta_{t r s} S$. On the other hand, another recent paper (Suzuki, 1984) claims a method for enhancing the accuracy of Cp measurements by DSC. Moreover, the attributed fundamental importance of heat capacity data--even in the region of thermal chaos--both theoretically and technologically, can usually be realized most efficiently and reliably by adiabatic calorimetry despite the fact that its systematic application to single and multicomponent systems has been limited by factors such as complicated instrumentation and prolonged (operator-involved) measurement periods. A few examples will reveal some of the details encountered.

\section{TRANSITIONS IN DNE-CONPONENT SYSTENS}

\section{Phase Transitions}

The theoretically truly-isothermal first order transition with concomitant infinite heat capacity is seldom seen reported in its pristine simplistic form. However, $\mathrm{NH}_{4} \mathrm{Br}$ is a prime example in the solid-solid transition at $412.66 \mathrm{~K}$ (Bartel et al., 1980). Here the molar heat capacity rises to values of $C_{p} / R$ of $10^{4}$ which do indeed approach infinity and 99.96 percent of the total (excess) enthalpy of the transition occurs over a temperature range only $0.004 \mathrm{~K}$ wide and pre- and post-transition effects are minimal. An impression of the $k$ ind of accuracy obtained through the transition region may be gained from comparison with the five (total) enthalpy increments and mapping runs covering the transition range with $H^{0}(444 \mathrm{~K})-H^{\circ}(387 \mathrm{~K})=8538.3,8542.0,8539.5,8533.3$, and 8535.8 (mean $=8537.9 \pm 1.6$ ) joules $\mathrm{mol}^{-1}$. Here the structural change is from a $\mathrm{CsCl-like} \mathrm{structure} \mathrm{to} \mathrm{a} \mathrm{NaCl-like} \mathrm{structure} \mathrm{and} \mathrm{is} \mathrm{accompanied} \mathrm{by} \mathrm{an} \mathrm{en-}$ thalpy increment $\Delta_{\text {trs }} S^{0} / R$ of $1.047 \pm 0.002$. Despite the sharpness of this transition--the sluggishness of energy uptake occasioned some serious problems in maintenance of adiabatic conditions. 


\section{Other Transitions}

Some substances reveal second-order "lambda transitions (Chang and Westrum, 1968) (occasionally associated with magnetic ordering) in which there is no isothermal absorption of energy.

Other transitions are more subtle, e.g., a glass transition for the passage of the amorphous glassy phase of an organic solid substance into the more fluid liquid phase (Carlson and Westrum, 1968). Relatively small enthalpy increments are involved and their magnitude, as seen in non-equilibrium measurements, are likely to be dependent on the scan rate.

Some substances, particularly salts of carboxylic acids, show a great variety of shapes, sizes, and disposition of transitions (Ngeyi et al., 1985) as shown in Figure 1, and even nondescript broad humps are seen (Ngeyi et al., 1986).

Provided due precautions are taken to ensure complete transformation on cooling, the transition regions can by suitable enthalpy increment and mapping runs have their thermophysical properties ascertained with an accuracy of a few hundredths of a percent. Moreover, should it be desirable to measure the transitional behavior on cooling, this is quite feasible by quantitative continuous cooling (Westrum and Burriel, 1985) or by more elaborate adiabatic techniques (Yoshimoto et a1., 1982).

In passing it should be noted the Schottky contributions arising from discrete electronic energy states (especially in $d$ - and f-element compounds) also represent important contributory features of transitions and may be evaluated spectroscopically--or even by adiabatic calorimetry (Gruber et a1., 1982; Chirico et al., 1980) provided a suitable means of evaluation of the usually much larger "lattice" contribution (Westrum, 1983) can be devised. Since individual Schottky contributions near $300 \mathrm{~K}$ are typically less than five percent of the total heat capacity, such resolutions must be made with high accuracy order/disorder transitions, and a host of named transitions too numerous to deal with here, deserve consideration, too. Very small--sometimes subtle gradual transitions--may be accurately studied upon addition of a high sensitivity, auxiliary thermometer and special shield control (Matsuo et al., 1973, 1974).

\section{BIMARY SYSTEMS}

Surprisingly enough, automated adiabatic calorimetry also provides an im- 


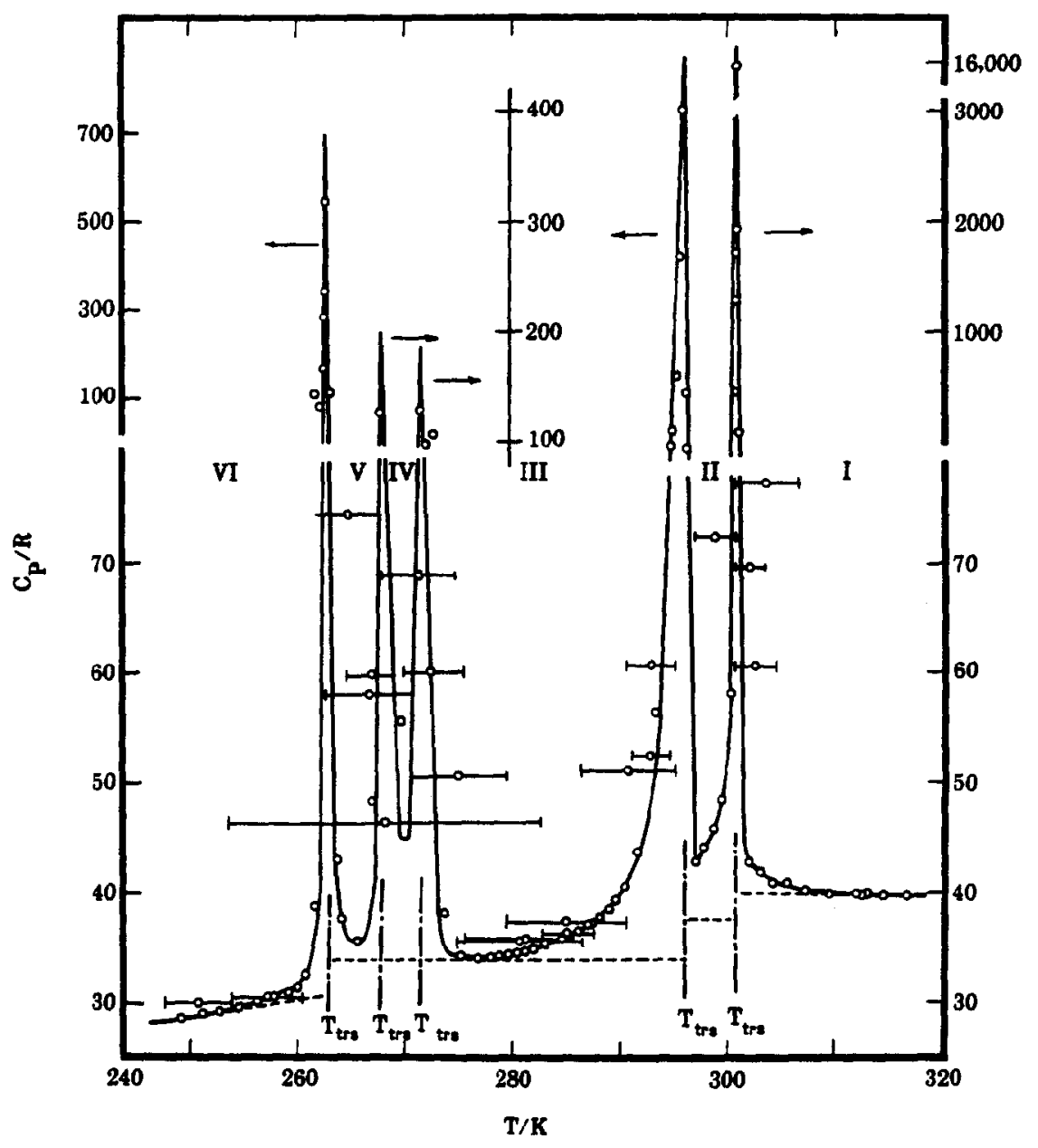

Fig. 1. Structural transition peaks of unknown origin (some probably involving reorientation of the hydrocarbon chains) in $\mathrm{CH}_{3}\left(\mathrm{CH}_{2}\right)_{5} \mathrm{COOTl}$. (Ngeyi et al, 1985)

pressive technique to delineate binary phase diagrams. As a matter of fact, even before automation, such endeavors were routine (Labowitz and Westrum, 1961; Euler and Westrum, 1961; Chang and Westrum, 1965; Chang and Westrum, 1970).

\section{$\mathrm{CC}_{4}-\mathrm{C}\left(\mathrm{CH}_{3}\right)_{4}$ System}

A binary system studied to ascertain if customary solution theories might not be more definitive for solid than for liquid solutions was the $\mathrm{CCl}_{4}$ $\mathrm{C}\left(\mathrm{CH}_{3}\right)_{4}$ system (Chang and Westrum, 1965). Here complex behavior extending to 
quite low temperature (e.g., a rotational transition near $140 \mathrm{~K}$ ) required reasonably long equilibration times in mapping transitions with increasing temperature. Cooling periods of about a week's duration were needed to ensure complete conversion.

Although the details of the results of the heat-capacity measurements will need to be sought in the original paper, the heat-capacity determinations were made on five mole fractions in the system tetramethylmethane-tetrachloromethane (Chang and Westrum, 1965; Chang and Westrum, 1970). The changes in temperature, magnitude, and shape of the anomalies in the heat capacity vs. temperature curves occasioned by composition variation indicated that for this system changes in molecular environment exert considerable effects on the reorientational-rotation transitions of the pure components. The melting point measurements are consistent with the existence of a continuous series of solid solutions immediately below the fusion temperature but require further investigation for definitive elucidation of the details. The expected lowering of the "rotational" $140 \mathrm{~K}$ transition of tetrachloromethane upon addition of tetramethylmethane is observed. The constancy at all the compositions studied of the tetramethylmethane transition temperature, $142.5 \mathrm{~K}$, indicated phase separation at this temperature. Eutectoid formation appears likely, judging from the occurrence of an intermediate transition at $191.6 \mathrm{~K}$.

Table 1 summarizes a small part of the thermal data for the transition regions of the five compositions plus that reported for the two pure components. The sum of the entropy increments of the transitions plus that of melting, is nearly identical for the five mixtures and are close to the values reported for the pure components.

The partial phase diagram for the system is depicted in Figure 2 on the basis of the adiabatic, equilibrium, calorimeter data.

In each of the compositions studied, Transition I appeared at the apparently constant temperature of $142.5 \mathrm{~K}$ and Transition II for the four tetrachloromethane-rich compositions appeared at $191.6 \mathrm{~K}$. The constancy of the Transition I temperature and the fact that its magnitude is directly proportional to the amount of tetramethylmethane in the sample, indicate that phase separation takes place above this temperature. Above here cooperative reorientational rotation is presumed to occur in the $\alpha_{1}$ phase transforming it to the phase designated $B_{1}$. Between Transitions I and II the phase diagram of 
TABLE 1. Summary of phase behavior for the system tetramethylmethane-tetrachloromethane (Units: cal, $g$ mol of solution, $K$ )

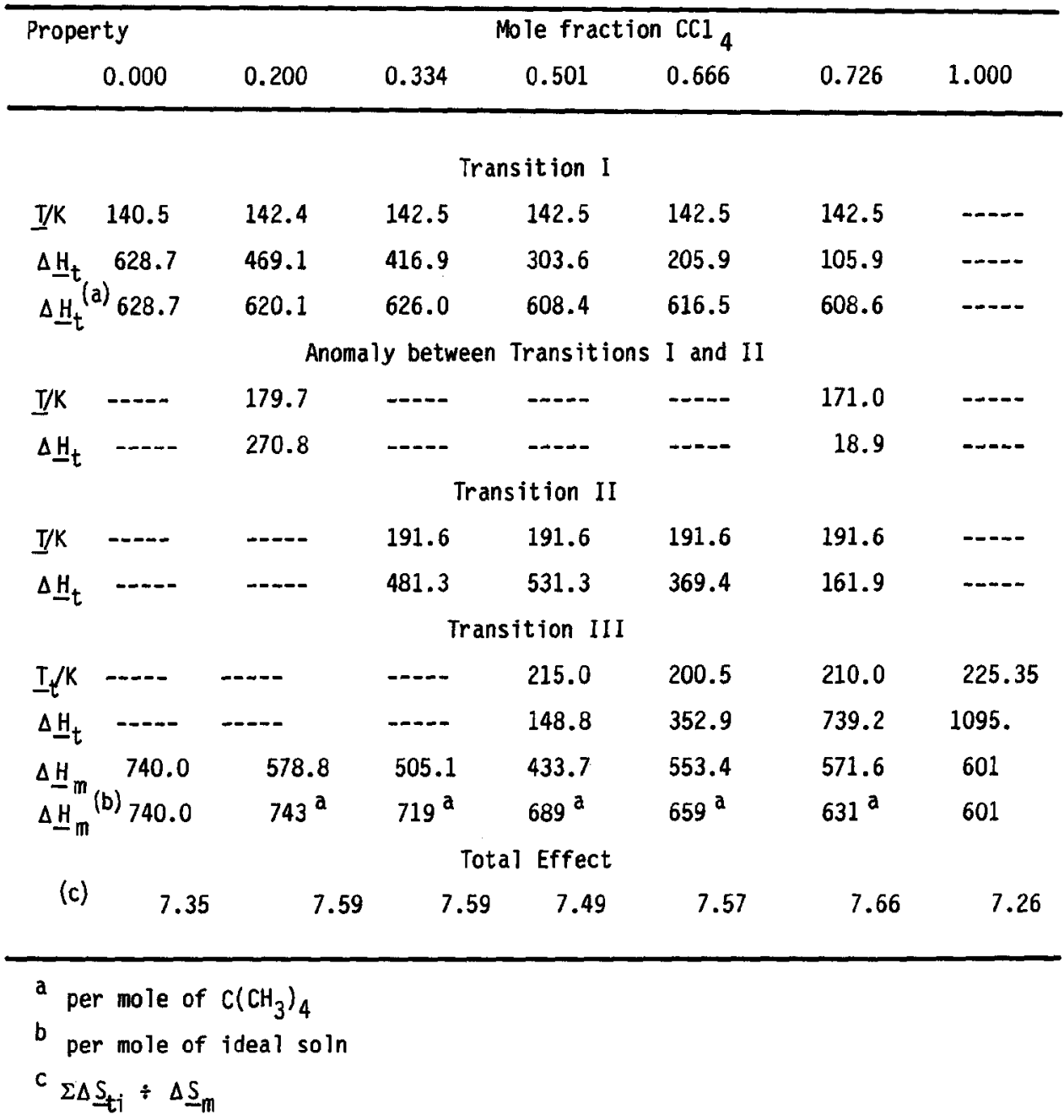

this system is divided into three regions: on the tetramethylmethane side is phase $\beta_{1}$, on the tetrachloromethane side is $\alpha_{2}$, and between is a two-phase region of $\beta_{1}+\alpha_{2}$. The "shoulder-like" heat-capacity anomaly that appears in the temperature range of $(170 \pm 5) \mathrm{K}$ may be due to increase in reorientational rotation in the $\beta_{1}$ phase.

Isothermal Transition II at $191.6 \mathrm{~K}$ is closely followed by Transition III in three of the tetrachloromethane-rich mixtures and the enthalpy increment of this transition reaches a maximum between the compositions with mole fractions 

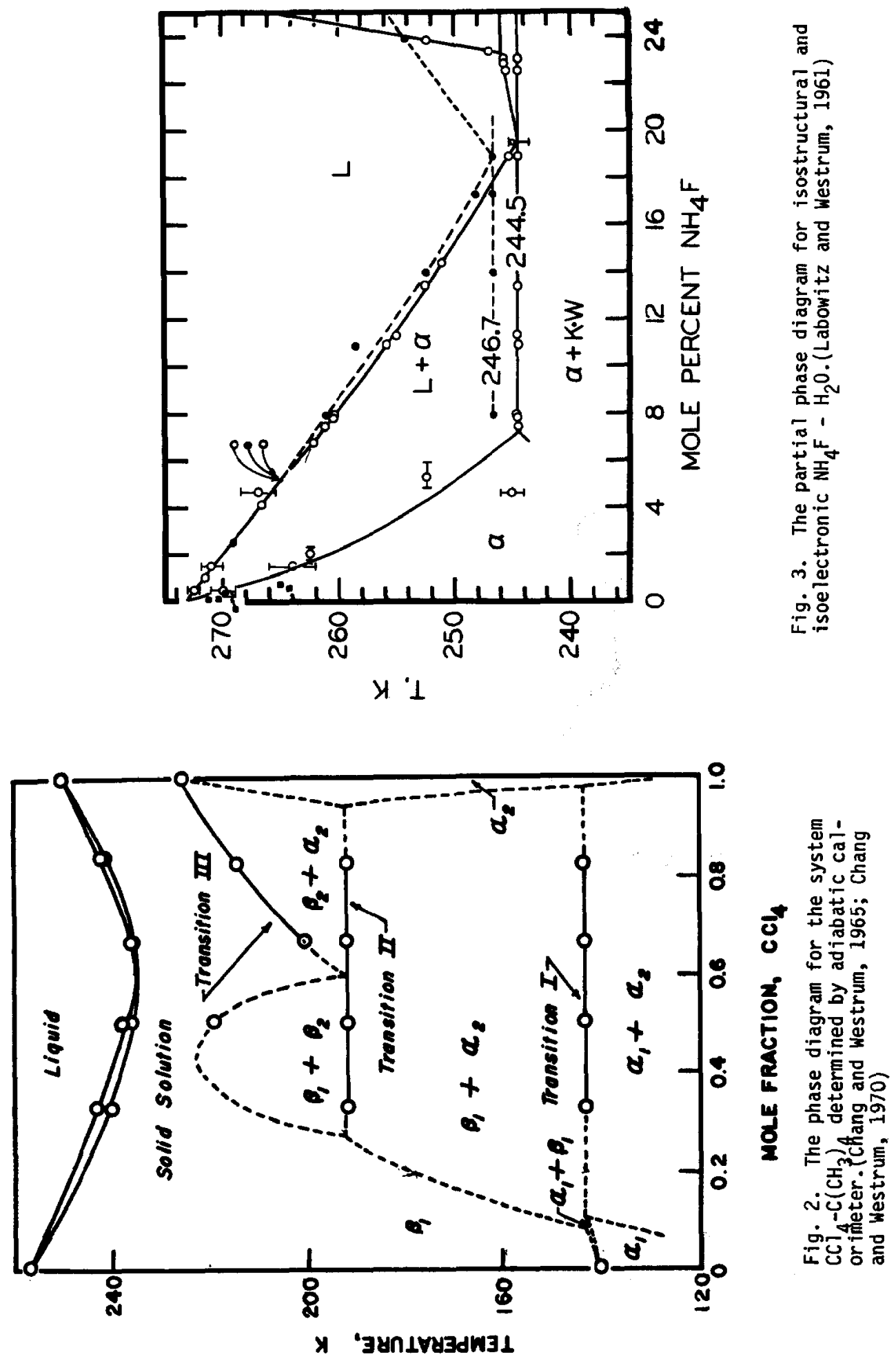
of $\mathrm{CCl}_{4}$ of 0.5 and 0.6 .

The data on compositions with mole fractions of $\mathrm{CCl}_{4}$ equal to 0.666 and 0.826 reveal the expected lowering of Transition III (the reorientational transition of tetrachloromethane) occasioned by the presence of tetramethylmethane. This transition may be interpreted as involving the onset of cooperative reorientational rotation in the $\alpha_{2}$ phase to form a homogeneous solid solution with $B_{2}$. Above the curve designating Transition III and below the melting curve, exist a continuous series of solid solutions.

\section{$\mathrm{NH}_{4} \mathrm{~F}-\mathrm{H}_{2} \mathrm{O}$ System}

A classical statement needing refutation was that ice does not form solid solutions. That this was incorrect was demonstrated by examining the extent of the eutectic line in the $\mathrm{NH}_{4} \mathrm{~F}-\mathrm{H}_{2} \mathrm{O}$ system (Labowitz and Westrum 1961). Not only are these compounds isostructural--they are also isoelectronic. As may be seen in Figure 3 the eutectic line at $244.5 \mathrm{~K}$ fails to come closer to the pure $\mathrm{H}_{2} \mathrm{O}$ composition than about nine mole percent. This unexpected finding was duly confirmed by Schreinemaker's method of wet residues in the ternary system $\mathrm{NH}_{4} \mathrm{~F}$ $\mathrm{HF}-\mathrm{H}_{2} \mathrm{O}$.

Although the solid-solution/two-phase boundaries often escape detection even in adiabatic calorimetry as can readily be understood on mathematical analysis, such calorimetry is able to detect the eutectic line to about three orders of magnitude more reliably than DTA or DSC and thus convey a capability of demonstrating its presence (or absence) within about 0.0002 mole fraction of the one-component boundary. In all the systems studied we have never seen a system that did not reveal evidence of solid solubility at both ends of the eutectic line(s)!

\section{CONCLUDING REMARKS}

By deliberately undercooling (or occasionally also by superheating) a phase into a region of metastability it is often possible to provide an unambiguous "lattice" heat capacity for resolution of enthalpies of transition, etc. This has been done for example in $\mathrm{CH}_{3} \mathrm{OH}$ (Carlson and Westrum, 1971) and in $\mathrm{Mn}_{0.63} \mathrm{Cr}_{0.37^{\text {As }}}$ (Komada and Westrum, 1986).

Methyl alcohol (Carlson and Westrum, 1971) provides a further convenient example of the influence of water--a contaminant--on the kinetics of the trans- 
formation. In the high-purity product obtained from a $10 \mathrm{~cm}$ diameter E.I. DuPont pipeline bearing $\mathrm{CH}_{3} \mathrm{OH}$ directly synthesized from the elements with a 99.98 percent purity--determined by fractional fusion--undercooling as much as $7 \mathrm{~K}$ and superheating of $2 \mathrm{~K}$ of the solid/solid transition was routine (actually unavoidable). In the presence of a trace of water yielding 99.88 percent purity, no under cooling or superheating was possible, and the heat capacity in the phase above the transition was significantly affected. Our measurements thus clearly demonstrated the first order nature of the transition in contrast with prior claims. What would even higher purity have done to our ability to even detect the transition?

In some systems, adiabatic calorimetry has mandated major modification of extant phase diagrams (Gronvold and Westrum, 1985).

Any transitions involving condensed phases--even tiny ferroelectric ones in thiourea (Westrum and Chang, 1967) involving $\Delta_{\text {trs }} S / R=$ about $0.02--m a y$ be quantitatively determined.

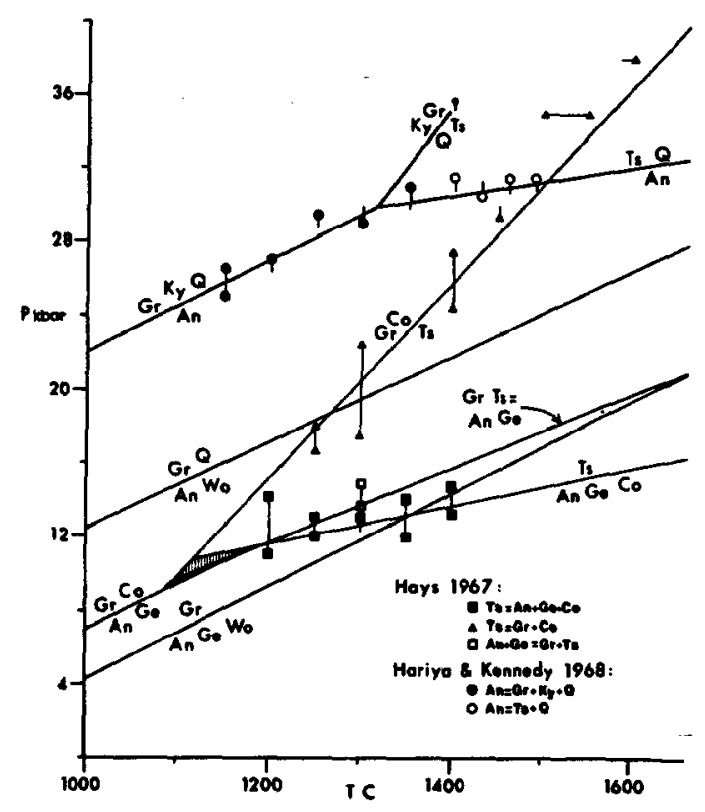

Fig. 4. Pressure-temperature mineralogical phase diagram comparing the thermodynamic extrapolations of a study on grossular with the experimental results of Hays and of Hariya and Kennedy. 
Finally, the use of adiabatic calorimetry to detect solid-insoluble/liquid-soluble impurities by fractional fusion (Westrum et al., 1968) should be mentioned. This provides an important test for solid-solution formation and for its quantitative enumeration by the treatment of Mastrange 10 and Dornte and is particularly relevant in an era of purification of molecularly crystalline materials by zone melting.

The complex phase diagrams for mineralogically relevant systems as seen in Figure 4, may be explored by Gibbs energies derived from heat capacities supplemented with a few equilibrium measurements, can only be hinted at in this brief exposition but will be elaborated in the oral presentation (Komada and Westrum 1986; Anovitz et al., 1985; Westrum, 1964).

Earlier relevant reviews have been published elsewhere (Westrum, 1966; Westrum, 1968; Westrum et a1., 1969; Westrum, 1977; Perkins et a1., 1980).

\section{REFERENCES}

Anovitz, L.M., A.H. Treiman, E.J. Essene, B.S. Hemingway, E.F. Westrum, Jr., V.J. Wall and R. Burriel, 1985. Geochim. Cosmochim. Acta, 49: 2027.

Andrews, J.T.S., P.A. Norton and E.F. Westrum, Jr., 1978. J. Chem. Thermodyn., $10: 949$.

Barte T, J.J., J.E. Callanan and E.F. Westrum,, Jr., 1980. J. Chem. Thermodyn., 12: 753 .

Carlson, H.G. and E.F. Westrum, Jr., 1968. J. Chem. Eng. Data, 13: 273.

Carlson, H.G. and E.F. Westrum, Jr., 1971. J. Chem. Phy., 54: 1464.

Chang, E.T. and E.F. Westrum, Jr., 1965. J. Phys. Chem., 69: 2176.

Chang, E.T. and E.F. Westrum, Jr., 1970. J. Phys. Chem., 74: 2528.

Chang, S.S. and E.F. Westrum, Jr., 1962. J. Chem. Phys., 36: 2420.

Chirico, R.D., E.F. Westrum, Jr. and J.B. Gruber, 1980. J. Chem. Thermodyn., 12: 311 .

Euler, R.D. and E.F. Westrum, Jr., 1961. J. Phys. Chem., 65: 1291.

Franzosini, P. and M. Sanesi, 1983. in Molten Salt Techniques. D.G. Lovering and R.J. Gale (Editors), Plenum, New York, p. 177.

Gill, P.S., 1974. Can. Research \& Development, i974: 23.

Gruber, J.B., R.D. Chirico and E.F. Westrum, Jr., 1982. J. Chem. Phys., 76: 4600 .

Gronvold, F. and E.F. Westrum, Jr., 1986 (in press). Data on the Cu $S$ system.

Komada, N. and E.F. Westrum, Jr., 1986 (in press). Work on Mn-Cr-As system..

Labowitz, L.C. and E.F. Westrum, Jr., 1961. J. Phys. Chem., 65: 408.

Matsuo, T., M. Tatsumi, H.Suga and S. Seki, 1973. Solid State Commun., 13: 1829 .

Matsuo, T., M. Tatsumi, H.Suga and S. Seki 1974. Proc. Japan Acad., 50: 476.

Ngeyi, S.P., F.L. Lopez de la Fuente, J.A.R. Cheda, F. Fernandez-Martin and E.F. Westrum, Jr., 1985. J. Chem. Thermodyn., 17: 409.

Ngeyi, S.P., E.F. Westrum, Jr. and P Franzosini, 1986 (in press). Data on the lithium pentanoate system.

Perkins, D., III, E.F. Westrum, Jr. and E.J. Essene, 1980. Geochim. Cosmochim. Acta., pp. 701. 
Suzuki, H. and B. Wunderlich, 1984. J. Therm. Anal., 29: 1369.

West, E.D. and E.F. Westrum,, Jr., 1968. in Experimental Thermodynamics, J.P. McCullough and D.W. Scott(Editors), Butterworth's, London, 1: 333.

Westrum, E.F., Jr., 1964. Pure and Applied Chemistry, 8: 187.

Westrum, E.F., Jr., 1966. Journal de Chimie Physique, 63: 462.

Westrum, E.F., Jr., 1968. in Analytical Calorimetry. R.S. Porter and J.F. Johnson, (Editors), Plenum Publishing Corp., New York, pp. 231.

Westrum, E.F., Jr., 1969. NBS Spec. Publ. 301: Washington, D.C.

R.S. Carter, and J.J. Rush (Editors), pp. 459.

Westrum, E.F., Jr., 1977. in Proceedings of the 1976 Calorimetry Conference, Zakopane, Poland, pp. 44.

Westrum, E.F., Jr., 1983. J. Chem. Thermodyn., 15: 305.

Westrum, E.F., Jr., 1984a. in Proceedings NATO Advanced Study Institute on Thermochemistry at Viana de Castello, Portugal, 1982. M.A.V. Ribeiro da Silva, (Editor). R.(Editor), Reidel, New York, pp. 671.

Westrum, E.F., Jr., 1984b. ibid,pp. 695.

Westrum, E.F., Jr., 1984c. ibid, pp. 745.

Westrum, E.F., Jr., 1986. (in press). in Specific Heat of Solids, A.R. Cezairliyan (Editor), Academic Press.

Westrum, E.F., Jr. and R. Burriel, 1985 (unpublished). Data on strained magnetic systems .

Westrum, E.F., Jr. and E.T. Chang, 1967. C.N.R.S. Transactions, 156: 163.

Westrum, E.F., Jr., G.T. Furukawa and J.P. McCullough,, 1968. in Experimental Thermodynamics. J.P. McCullough and D.W. Scott,(Editors), Butterworth's, London, 1: 133.

White, M.A., 1984. Thermochimica Acta., 74: 55.

Yoshimoto, Y., T. Atake and H. Chihara,, 1982. Netsusokutei, 9: 57. 